\title{
Message in a Bottle: Operations and Epistemology of an Explorative Drifter [Video]
}

\author{
Sotiria Lampoudi ${ }^{a}$, Christina Vagt ${ }^{b}$ \\ Keywords: citizen science, drifter, oceanography, epistemic things \\ https://doi.org/10.1525/001c.22193
}

Despite marine sciences' turn towards big data over the last decades, only a very small portion of the world's oceans today are sufficiently understood. Their modeling requires constant research and development of new ocean technologies, a highly competitive field usually conducted by corporate industries or public research institutions. In this case, an ocean robotics engineer and a media theorist met over the summer of 2019 in Santa Barbara to explore and reflect on alternative approaches in the design process of oceanographic data engineering and the role that media theory could play in it. They built and deployed a GPS trackable floating device that provided some in situ data from the Santa Barbara Channel, and posed many open questions. The field report speaks of obstacles and failures, as well as surprising results and insights in the design process.

Video available at: https://vimeo.com/527395527

\footnotetext{
a Sotiria Lampoudi, PhD is a computer scientist, now working as the Chief Software Architect at Hefring Engineering. While still a postdoc at UCSB she designed the Las Cumbres Observatory's global robotic telescope network scheduling kernel, which enables the continuous observation of targets despite the Earth's rotation. Since 2013 she has worked in industry and non-profit robotics for science, with an emphasis on multi-robot coordination. At Liquid Robotics she was part of the team that built the Wave Glider Autonomous Surface Vehicle (ASV); at DroneSeed she designed multi-UAV (Unmanned Aerial Vehicle) coordination algorithms, resulting in the first waiver from the FAA permitting operation of multiple drones under the supervision of a single pilot; and at Monterey Bay Aquarium Research Institute (MBARI) she was part of the team that integrated the first "back-seat driver" payload onto the Long Range Autonomous Underwater Vehicle (LRAUV).

b Christina Vagt is Associate Professor of European Media Studies at the UCSB's Department of Germanic \& Slavic Studies. She teaches history and theory of media, science and literature, as well as European philosophy. Her research focuses on epistemic and aesthetic relations between sciences and humanities and the role that media and technology play in it. Before joining UCSB in 2017, she taught history and theory of culture at Humboldt Universität zu Berlin, literature and science at Technische Universität Berlin and History and Theory of Media at Bauhaus Universität Weimar.

Books: Geschickte Sprünge. Physik und Medium bei Martin Heidegger (Diaphanes 2012); Action at A Distance, coedited with John Durham Peters, Florian Sprenger (Minnesota Uni. Press / Diaphanes 2020); Verhaltensdesign. Technologische und ästhetische Programme der 1960er und 1970er Jahre, co-edited with Jeannie Moser (Transcript 2018), and The Afterlife of Systems, a special issue of communication+1, co-edited with Florian Sprenger.
} 


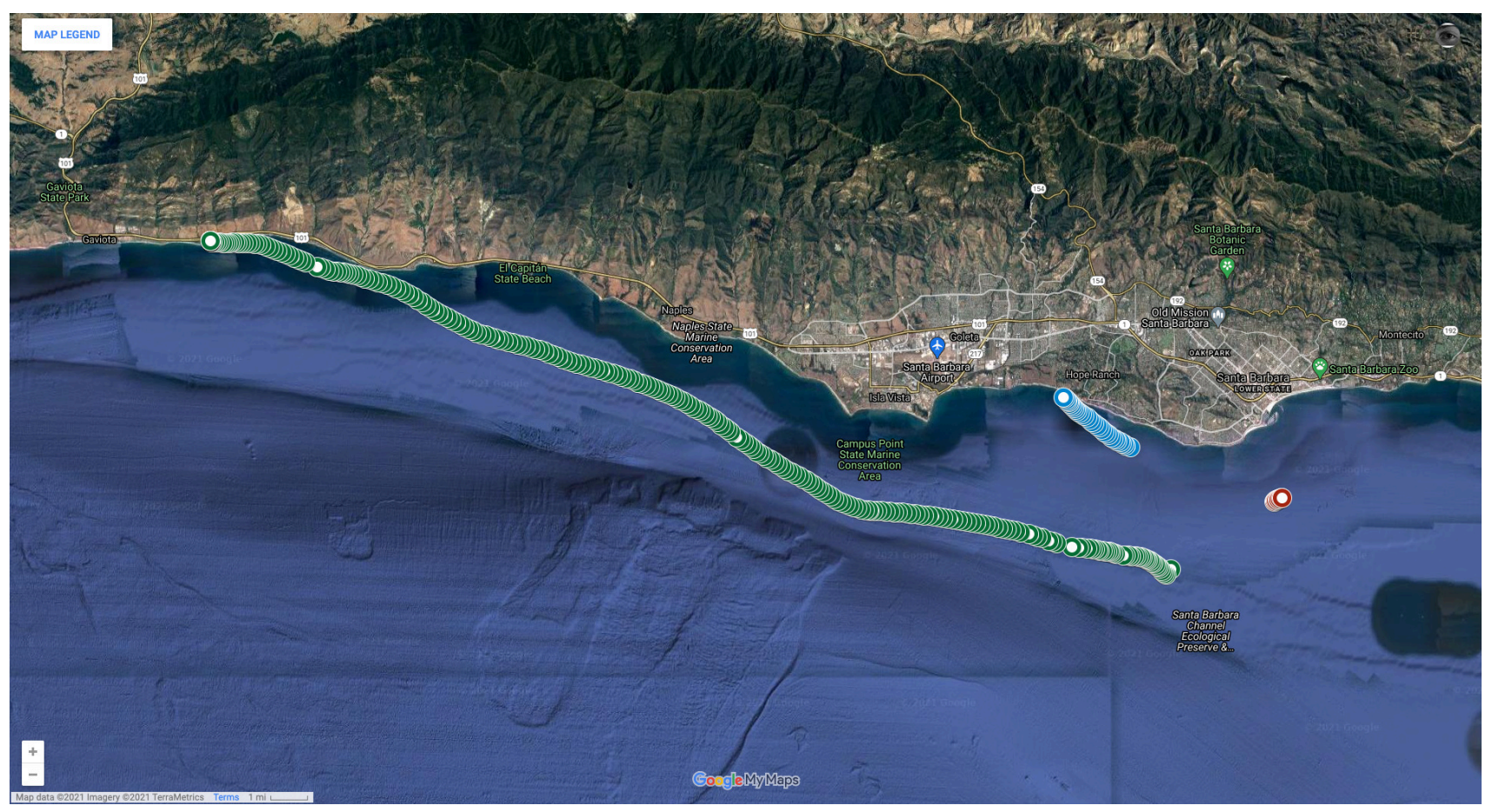

Figure 1: The three deployments of the MiB [Message in a Bottle]

Google Maps screenshot by S. Lampoudi. 